\title{
Do "Myths" of low back pain exist among young Indian college-going adults with a history of low back pain? A cross-sectional study
}

\author{
Ammar Suhail ${ }^{1 *}$ (D) Sonal Slathia ${ }^{1}$, Sarah Quais $^{2}$ (D) and David C. Poulter ${ }^{3}$ (D)
}

\begin{abstract}
Background: Low back pain (LBP) is a prominent public health problem which causes disability around the globe. The prevalence of LBP is on the rise in lower to middle-income countries. India has a varied prevalence of LBP among the rural as well as urban population ranging from 6.2 to $92 \%$. There has been a marked increase in young adults getting LBP with a proportion converting to chronic LBP later in life. Beliefs associated with any disorder affect the course, management, and need for imaging studies. Negative beliefs about LBP in any population may lead to unnecessary psychologic distress and an increase in disease burden. Focusing these negative beliefs on the younger population can help curb the chronicity and lessen the disability caused by it. This cross-sectional study explored the presence of myths in 516 college-going Indian young adults from Lovely Professional University.
\end{abstract}

Results: A total of 516 individuals participated in the study. The mean (SD) age of the participants was 22.69 years (2.417). Among them, $47.5 \%$ (245) were females and 52.5\% (271) were males. The findings show that a high percentage of college-going young adults have false beliefs in most of the ten domains (myths) explored. The most prevalent myths were "LBP is caused by weak 'core' muscles and having a strong core protects against future LBP" $(81.2 \%)$ and "LBP is caused by poor posture when sitting, standing, and lifting" with $80.6 \%$ agreeing to it.

Conclusion: Our study demonstrated that the myths of low back pain are widespread among the studied population. The findings suggest that community education programs must be developed to address these myths, hence reducing the disease burden associated with back pain.

Keywords: Low back pain, Myths, Beliefs, Biopsychosocial model, Posture

\section{Background}

Low back pain (LBP) is an almost ubiquitous pain disorder among all populations in the world [1]. It has evolved as a significant public health problem [2]. It continues as the most prominent cause of years lived with disability around the globe [3]. A nationwide study from Thailand suggested that LBP is a frequent public health problem among economically productive age groups [4].

\footnotetext{
*Correspondence: asuhail38@gmail.com; ammar.19815@lpu.co.in

'Department of Physiotherapy, Lovely Professional University, Phagwara,

Punjab, India

Full list of author information is available at the end of the article
}

The increase in prevalence is more rapid in lower and middle-income countries [1]. Estimates range from a prevalence of $58-84 \%$ for adults who will experience LBP at some point in their life [5]. The Global Burden Study suggested that LBP is the leading health disorder contributing to the need for rehabilitation services in 134 of 204 countries [6].

The prevalence of LBP in India is reported to be between 6.2 and 92\%; the huge variation is attributed to the heterogeneity of the conducted studies [7]. In a study conducted among rural women in Puducherry, India, the prevalence was reported as $42 \%$ [8]. Indian youth are 
at higher risk of development of LBP similar to their western counterparts [9]. Despite the high prevalence of LBP, it can be a self-limiting disorder that resolves in most in a few weeks, but studies have shown that a small group of people (5-10\%) who experience LBP may develop chronic LBP [10-14]. It is suggested that beliefs about LBP can influence the course and treatment sought for the disorder.

Beliefs are defined as "Something one accepts as true or real; a firmly held opinion" (Oxford dictionary). Sometimes irrational beliefs associated with pain predict the disability and chronicity of pain $[9,15-17]$. The primary concern about LBP beliefs has recently been highlighted in an editorial written by O'Sullivan and colleagues. They outlined ten myths surrounding LBP, its course, management, and the need for imaging. A general lack of factual knowledge surrounding the management of LBP can lead to eventual chronicity and increased psychologic distress and affect behaviors and self-efficacy [18].

Previous studies have documented that wrong beliefs are prevalent among diverse study populations $[2,5,19$, 20]. In a study conducted in Ireland, it was found that myths of LBP widely existed among the Irish population [2]. Similar results were established in a study among the Norwegian population which reported a high prevalence of myths associated with LBP [20]. There is a paucity of evidence about wrong beliefs in the Indian population. Given this gap in the literature, we set out to test the hypothesis whether beliefs about myths surrounding LBP would be common in this cohort of young college-going adults.

Beliefs formed in early life can lead to the chronicity of back pain in later life. Studies have found that LBP is common among young adults, with incidence peaking in the third decade of life [9]. Moreover, young LBP is a strong predictor of the development of LBP in middle to older age adults [21]. Identification of wrong beliefs at a younger age will help healthcare providers in reducing the disease burden associated with LBP. These wrong beliefs can be targeted in young adults to ensure that LBP does not progress to a chronic disease state $[9,18]$. Therefore, the objective of the study was to identify the presence of myths about LBP in young college-going adults.

\section{Methods}

\section{Study design}

This was designed as a cross-sectional study to explore beliefs about LBP among college-going adults. The study was conducted at Lovely Professional University, Phagwara, Punjab, India. The data was collected from December 2019 to March 2020. There were no follow-up data collected from the respondents. The study was conducted and reported in accordance with the STROBE guidelines.

\section{Ethics}

The study was approved by the Institutional ethical committee Lovely Professional University, approval number LPU/IEC/2019/03/13. Before enrollment, a written informed consent was signed by all the participants. Participation in the study was voluntary, and the authors had no role in student's grades and academic evaluations. Ethical principles of the study adhered to the principles laid down by the World Medical Association (WMA) Declaration of Helsinki [22].

\section{Participants}

College-going adults belonging to different streams between the age of 18 and 29 years old were recruited in the study. Participants must have had an episode of low back pain once in a lifetime. We chose to exclude any individual currently undergoing or have taken physiotherapy management for LBP as we thought this might have already influenced their beliefs surrounding LBP. We identified different departments in the university, and from each department, participants were recruited using a convenient sampling method.

\section{Sample size}

The sample size was calculated using Solvin's formula. The power of sample size was calculated using a $95 \%$ confidence interval with a $5 \%$ margin of error. The calculated sample size equals $n=N \div\left(1+N e^{2}\right)$ people, where $n$ is the number of samples, $N$ is the total number of population, and $e$ is the margin of error. Thus, $n=N$ / $\left(1+N e^{2}\right)=35,000 /\left[1+\left\{35,000 \times(0.05)^{2}\right\}\right]=35,000 / 88.5$ $=396$. We recruited a greater number of participants to adjust for non-respondents and to increase the generalizability of the findings. Five hundred and sixteen college-going adults conclusively participated in our study.

\section{Procedure}

Participants were invited to fill the survey in person by the second author. She visited different departments of the Lovely Professional University (Punjab) to gather responses to the survey. The survey document consisted of a patient information sheet (highlighting study's aims and objectives), a consent form, and the questionnaire. The participants were requested to read the instructions carefully and then proceed ahead; the consent form was signed if they agreed to participate in the study. Followed by this, participants filled the survey anonymously and the data was documented. 


\section{Survey instrument}

We adapted belief statements (Table 1) based on the editorial written by O'Sullivan and colleagues [18]. In this editorial and infographic, they identified ten common unhelpful beliefs about LBP. This is the first study utilizing these belief statements. The responses were graded as agreed or disagreed with the statements. The survey was divided into three subsections: the first section included details about the study and the consent form, followed by the second section related with the demographic characteristics of the participants. The third section consisted of back pain belief statements, to which participants could either agree or disagree. The full survey is available as Additional file 1 .

\section{Data analysis}

SPSS version 20 was used to analyze the data. The survey was analyzed using descriptive statistics; the study data was summarized through ordinal and nominal data, expressed in frequencies, percentages, mean, and standard deviations. The differences between responses on the basis of gender and education were analyzed using Fisher's exact test.

\section{Results}

\section{Demographic characteristics}

A total of 516 individuals participated in the study. The mean (SD) age of the participants was 22.69 years (2.417). Among them, $47.5 \%$ (245) were females and $52.5 \%$ (271) were males. In terms of educational level, $77.9 \%$ (402) of participants were undergraduates and $22.1 \%$ (114) were postgraduates. The other basic characteristics of the participants are highlighted in Table 2 . The participants belonged to 22 different states and union territories of India (Fig. 1).

Table 1 Back pain belief statements

Myth 1: LBP is usually a serious medical condition.

Myth 2: LBP will become persistent and deteriorate in later life.

Myth 3: Persistent LBP is always related to tissue damage.

Myth 4: Scans are always needed to detect the cause of LBP.

Myth 5: Pain related to exercise and movement is always a warning that harm is being done to the spine and a signal to stop or modify activity.

Myth 6: LBP is caused by poor posture when sitting, standing, and lifting

Myth 7: LBP is caused by weak "core" muscles, and having a strong core protects against future LBP.

Myth 8: Repeated spinal loading results in "wear and tear" and tissue damage.

Myth 9: Pain flare-ups are a sign of tissue damage and require rest.

Myth 10: Treatments such as strong medications, injections, and surgery are effective and necessary, to treat LBP.
Table 2 Demographic characteristics of the participants

\begin{tabular}{|c|c|c|}
\hline Variables & Frequency $(n)$ & Percentage (\%) \\
\hline Mean (SD) age (years) & 22.69 & 2.41 \\
\hline Male & 271 & 52.5 \\
\hline Female & 245 & 47.5 \\
\hline \multicolumn{3}{|l|}{ Education level } \\
\hline Undergraduate & 402 & 77.9 \\
\hline Postgraduate & 114 & 22.1 \\
\hline \multicolumn{3}{|l|}{ Smoking } \\
\hline Yes & 295 & 57.2 \\
\hline No & 221 & 42.8 \\
\hline \multicolumn{3}{|l|}{ Physically active } \\
\hline Yes & 271 & 52.5 \\
\hline No & 245 & 47.5 \\
\hline \multicolumn{3}{|l|}{ Family history of LBP } \\
\hline Yes & 216 & 41.9 \\
\hline No & 300 & 58.1 \\
\hline \multicolumn{3}{|l|}{ Treatment for LBP } \\
\hline Yes & 286 & 55.4 \\
\hline No & 230 & 44.6 \\
\hline \multicolumn{3}{|l|}{ Treatment strategies } \\
\hline Exercises & 26 & 5.0 \\
\hline Gel & 5 & 1.0 \\
\hline Hot pack & 88 & 17.1 \\
\hline Massage & 6 & 1.2 \\
\hline Medicines & 137 & 26.6 \\
\hline Rest & 4 & 0.8 \\
\hline Yoga & 6 & 1.2 \\
\hline No treatment & 244 & 47.3 \\
\hline
\end{tabular}

The data are presented as frequency and percentages unless specified otherwise

\section{Beliefs associated with LBP}

Regarding the beliefs about LBP, all the myths were prevalent among the study participants. Table 3 highlights the specific numbers and percentages of participants holding wrong beliefs. Figure 2 depicts the percentages in graphical form.

\section{Gender and education impact on responses}

We analyzed the data to explore whether there was any difference in myth prevalence based on gender and education (Tables 4 and 5). The majority of wrong beliefs were common across both genders. Myth 1 (LBP is usually a serious medical condition) was more prevalent in females (72\% agreed) as compared to males $(63.3 \%$ agreed) $(p=0.03)$. Similarly, myth 2 (LBP will become persistent and deteriorate in later life) was also more common among female participants (76.4\% agreed), 


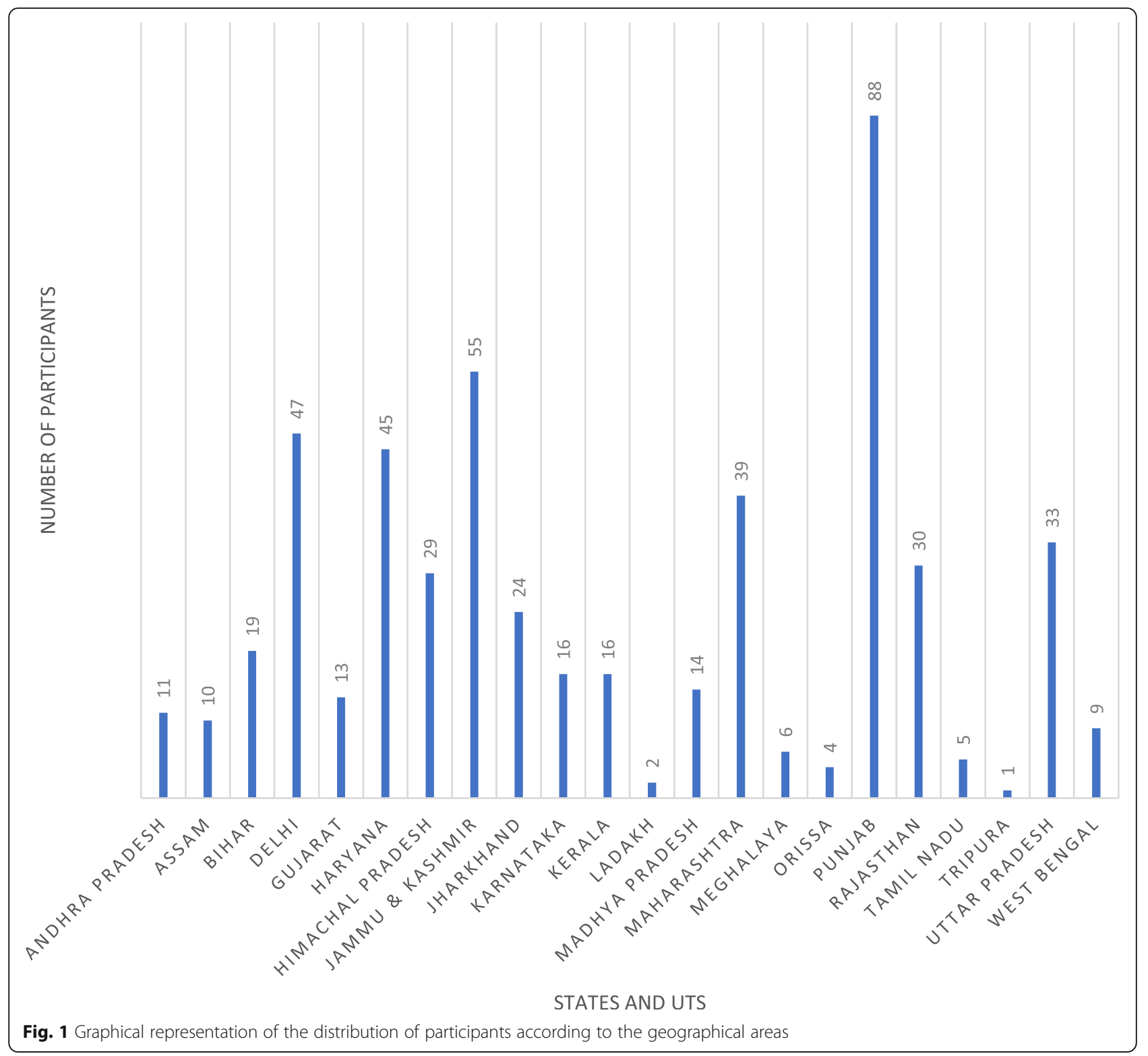

whereas in their male counterparts, $73.1 \%$ agreed ( $p=$ 0.38 ). There was a statistically significant difference in responses for myth 8 (Repeated spinal loading results in "wear and tear" and tissue damage) where $70.2 \%$ of male participants agreed to the negative belief while in female participants, only $61.6 \%$ agreed to it $(p=0.40)$. For education, the data did not show any statistical differences between the undergraduates and the postgraduates.

\section{Discussion}

The findings of our study suggest that a high percentage of college-going young adults have false beliefs in most of the ten domains (myths) surrounding LBP course, prognosis, relationships to tissue damage, and imaging needs. The most prevalent wrong beliefs were related to core muscle strength $(81.2 \%)$ and poor posture $(80.6 \%)$. The only myth with the least diverse response was related to "Treatments such as strong medications, injections, and surgery are effective, and necessary, to treat LBP," with relatively minimal difference in the percentage of people agreeing (44.6\%) or disagreeing (55.4\%) with the statement.

Our study results are in line with similar studies on LBP beliefs [2, 19-21, 23, 24]. Our results can be compared with a similar study conducted in Pune, India. It studied myths among the general population aged 1860 years which reported a similar prevalence too [24]. The only difference from their findings was that people 
Table 3 Beliefs about LBP among the study participants

\begin{tabular}{llllll}
\hline Myths & \multicolumn{2}{l}{ Frequency } & & \multicolumn{2}{l}{ Percentage } \\
\cline { 2 - 3 } & Yes & No & & Yes & No \\
\hline M1 & 350 & 166 & 67.8 & 32.2 \\
M2 & 386 & 130 & & 74.8 & 25.2 \\
M3 & 316 & 200 & 61.2 & 38.8 \\
M4 & 303 & 213 & 58.7 & 41.3 \\
M5 & 365 & 151 & 70.7 & 29.3 \\
M6 & 416 & 100 & 80.6 & 19.4 \\
M7 & 419 & 97 & 81.2 & 18.8 \\
M8 & 339 & 177 & 65.7 & 34.3 \\
M9 & 360 & 156 & 69.8 & 30.2 \\
M10 & 230 & 286 & 44.6 & 55.4 \\
\hline
\end{tabular}

M1-M10 are myth statements highlighted in Table 1

agreed to surgery being an important treatment option whereas in our study $55.8 \%$ of participants disagreed with this belief. This disagreement in results could be attributed to the young age of participants in our study.

We did not have a statistically significant difference in responses between the undergraduates and postgraduates. These findings are in contradiction to the previous study conducted in the Irish population [2]. In their study, education played an important role in the prevalence of wrong beliefs among the community. The differences in the results of both studies may be ascribed to the studied population and geographical variation. The age of their sample was highly variable (18-60 years) whereas we included young college-going adults.

Similarly, gender-based responses in our study showed no statistical significance which is similar to the findings of Munigangaiah et al. [2]. We found a statistical difference in terms of three myths. Myth 1 (LBP is usually a serious medical condition) and myth 2 (LBP will become persistent and deteriorate in later life) were agreed upon more by the female participants with a response of $72 \%$ and $76.4 \%$, respectively. This gender-based significant difference may be related to catastrophizing of pain among females which is influenced by various negative cognitive and affective responses to pain [25]. On the contrary, $70.2 \%$ of male participants agreed to myth 3 (repeated spinal loading results in "wear and tear" and tissue damage).

Studies have shown that the presence of false beliefs among individuals contributes to the development of disability associated with LBP [24]. False beliefs associated with LBP lead to overutilization of health care and increased use of advanced imaging, leading to a spiraling increase in healthcare costs [18]. Our study found that $67.8 \%$ and $74.8 \%$ of participants agreed to the myth "LBP is usually a serious medical condition" and "LBP will become persistent and deteriorate in later life," respectively. These two strong wrong beliefs may contribute to pain catastrophe, fear avoidance, and absenteeism from work [16, 20]. Recent evidence suggests that LBP can be distressing but is rarely a lifethreatening problem $[18,24]$.

In the present study, $61.2 \%$ of participants believed that LBP is associated with some tissue damage, contrary to the evidence which suggests spines are strong and robust. Most LBP patients do not have a preceding cause and are termed as nonspecific LBP, suggesting that the pathoanatomical etiology is unknown $[18,26]$. A recent study in young Indian adults reported that the development of LBP is associated with marital status, previous history of spine problems, strenuous exercise, job satisfaction, monotony, stress, daily study hours, and family history of spine problems [9]. A total of $54.8 \%$ individuals believed scans are useful in identifying the source of pain in LBP patients. Longitudinal studies have shown that changes visible on scans are not associated with patients' symptoms. Moreover, these studies suggest that changes documented on magnetic resonance imaging scans are normal age-related differences present even in asymptomatic individuals [27-29]. False beliefs about the need for early advanced imaging in LBP have been linked to worse outcomes and increased LBP episode duration $[23,30]$. Thus, we suggest more importance must be given to good history taking and clinical examination while reserving diagnostic imaging for only the most needed cases.

The majority of the participants approved that pain related to movement is a warning sign (70.7\%) and repeated spine loading causes wear and tear (65.7\%). These beliefs have no basis in the literature; movementand exercise-related pain reflect how sensitive structure is and not how damaged they are [18]. There is strong evidence suggesting that advice to stay active despite the pain results in better reductions in pain and associated disability [31, 32]. LBP that is caused by poor posture was agreed by $80.2 \%$ and even a higher number of participants (81.2\%) agreed that LBP is caused by weak "core." Scientific evidence suggests posture is not associated with pain and moreover regular variation of different postures are essential for a healthy spine [18]. Similarly, the evidence that a weak core causes back pain does not hold water [18]. The myth "Pain flare-ups are a sign of tissue damage and require rest" was agreed upon by $69 \%$ of participants. Literature has identified that flare-ups can be caused by multiple factors like poor sleep, stress, anxiety, and low mood. Addressing these factors is much more critical to look after an acute flareup [18].

The last myth had a relatively equal proportion of participants agreeing and disagreeing about 
Treatments such as strong medications, injections, and surgery are effective and necessary, to treat LBP

Pain flare-ups are a sign of tissue damage and require rest

Repeated spinal loading results in 'wear and tear' and tissue damage

LBP is caused by weak 'core' muscles, and having a strong core protects against future LBP.

LBP is caused by poor posture when sitting, standing, and lifting

Pain related to exercise and movement is always a warning that harm is being done to the spine and a signal to stop or modify activity

Scans are always needed to detect the cause of LBP

Persistent LBP is always related to tissue damage

LBP will become persistent and deteriorate in later life

LBP is usually a serious medical condition
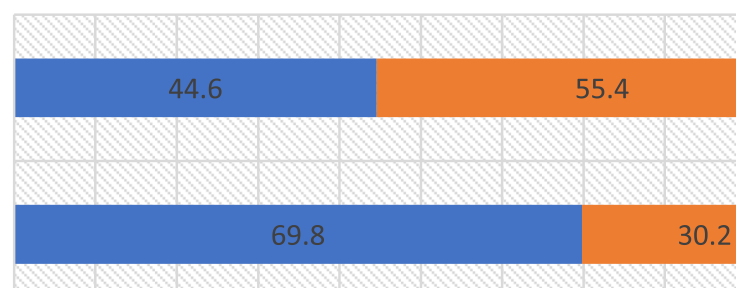

\section{.2}

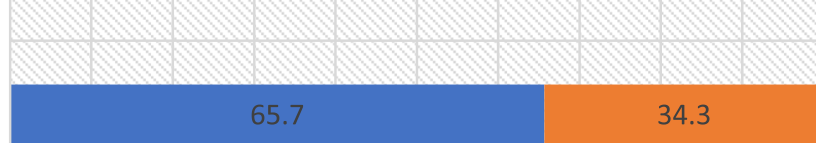

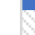
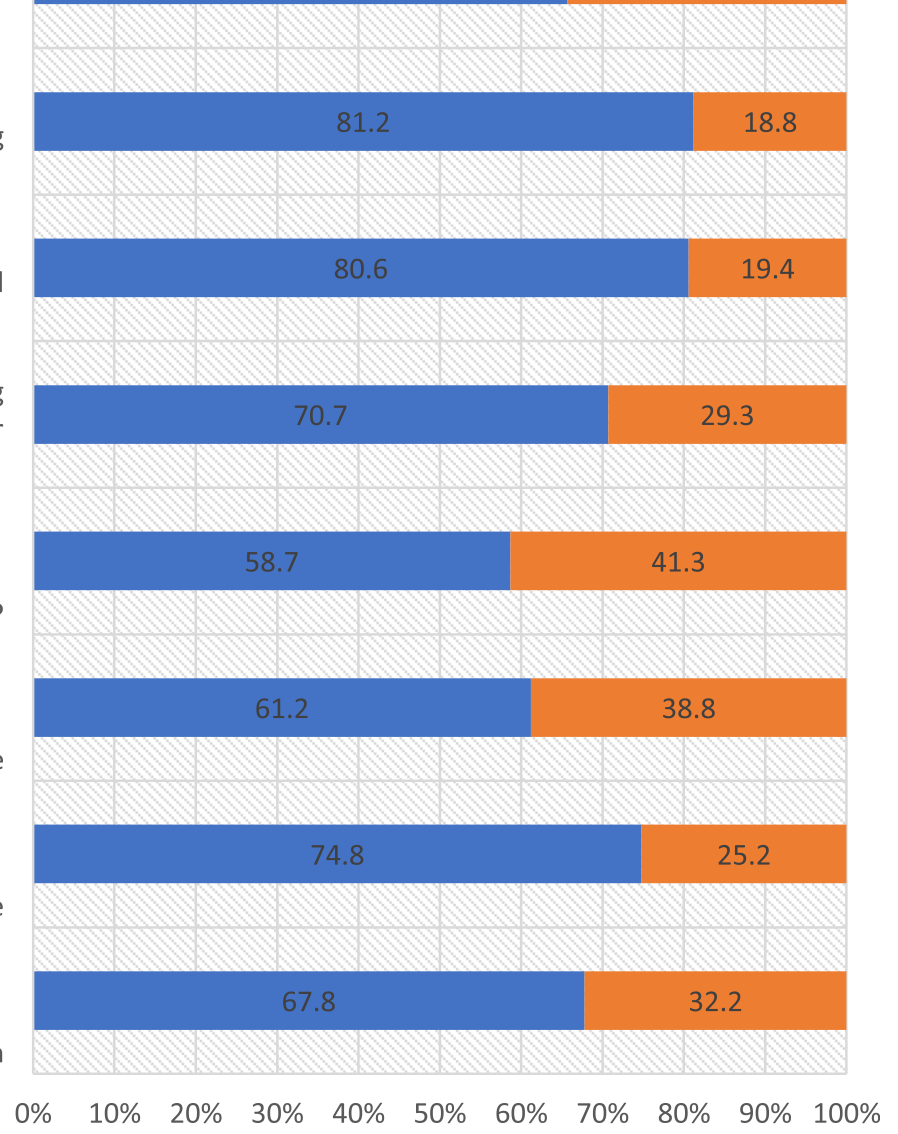

Agree $\quad$ Disagree

Fig. 2 Graphical representation of frequencies (\%) of individuals responding as agreeing or disagreeing for the belief's statements associated with LBP

treatment options for LBP where $44.6 \%$ of participants agreed that "Treatments such as strong medications, injections, and surgery are effective, and necessary, to treat LBP," while $55.4 \%$ disagreed with this statement. Beliefs related with LBP are often developed after seeking care for an episode of LBP. The study findings stress the need to study the myths and their impact on patient care. Clinicians may hold false beliefs and pass these onto their patients, compounding the myths and leading to unintended consequences [33]. Recent studies on community education around the evidence on LBP have been directed both at treating clinicians and patients, with promising results [34-36].

Given the evidence that such beliefs may lead to increased healthcare costs, overutilization of advanced imaging, prolonged episodes of LBP leading to chronic LBP in some [37], there may be a need for a communitybased education program. Future research can be aimed at developing an education program and reevaluating our survey to assess the effect. The biggest challenge that we face is to change the beliefs and understanding 
Table 4 Evaluation of the responses based on gender

\begin{tabular}{|c|c|c|c|c|c|c|}
\hline \multirow[t]{2}{*}{ Myths } & \multirow{2}{*}{$\begin{array}{l}\text { Pearson } \\
\text { chi- } \\
\text { square }\end{array}$} & \multicolumn{2}{|l|}{ Male } & \multicolumn{2}{|l|}{ Female } & \multirow{2}{*}{$\begin{array}{l}p \\
\text { value }\end{array}$} \\
\hline & & Agree (\%) & Disagree (\%) & Agree (\%) & Disagree (\%) & \\
\hline M1 & 4.45 & 63.3 & 36.7 & 72 & 28 & $0.03^{*}$ \\
\hline M2 & 0.75 & 73.1 & 26.9 & 76.4 & 23.6 & 0.38 \\
\hline M3 & 1.58 & 64.1 & 35.9 & 68.6 & 31.4 & 0.21 \\
\hline M4 & 10.2 & 51.4 & 48.6 & 65.3 & 34.7 & $0.01 *$ \\
\hline M5 & 1.21 & 73.1 & 26.9 & 68.6 & 31.4 & 0.27 \\
\hline M6 & 1.49 & 82.9 & 17.1 & 78.6 & 21.4 & 0.22 \\
\hline M7 & 0.83 & 82.9 & 17.1 & 79.7 & 20.3 & 0.36 \\
\hline M8 & 4.20 & 70.2 & 29.8 & 61.6 & 38.4 & $0.40^{*}$ \\
\hline M9 & 0.42 & 70.2 & 29.8 & 69.4 & 30.6 & 0.83 \\
\hline M10 & 1.45 & 47.3 & 52.7 & 42.1 & 57.9 & 0.22 \\
\hline
\end{tabular}

${ }^{*} \mathrm{M} 1-\mathrm{M} 10$ are myth statements highlighted in Table 1 and the $p$ value is significant at $<0.05$. Each row represents one question. The percentage of agreement and disagreement for each gender and the $p$ value for the chi-square test of independence are shown

of treating clinicians associated with LBP and its management. Any education program must be aimed at both patients and clinicians to ensure the best outcomes [34, 35]. Strategies to educate the community about clear and correct information about LBP are required to address the increasing LBP burden among diverse population groups.

Our study had few strengths; first, this is the first study among young adults in the Indian population to our informed knowledge. Second, we were able to include participants from 22 different states and union territories and thus had a diversity in the sociocultural context. We would also like to acknowledge the limitations of our study. Primarily, the findings of this study hold ground only for a specific age group. The other limitation is attributed to the study design as the study's nature is cross-sectional which is applicable within a time frame and among the accessible population.

\section{Conclusion}

We concluded that the myths surrounding LBP are common among young college-going Indian adults with history of LBP. The two most prevalent myths were that LBP is caused by weak "core" muscles and poor postures in standing, sitting, and lifting results in back pain. Government health bodies must direct future resources at the development of a community education program to reduce the burden of low back pain. The effectiveness of these community programs must be evaluated in large longitudinal studies in different parts of India.

Table 5 Evaluation of the responses based on educational level

\begin{tabular}{|c|c|c|c|c|c|c|}
\hline \multirow[t]{2}{*}{ Myths } & \multirow{2}{*}{$\begin{array}{l}\text { Pearson } \\
\text { chi- } \\
\text { square }\end{array}$} & \multicolumn{2}{|c|}{ Undergrads } & \multicolumn{2}{|l|}{ Postgrads } & \multirow{2}{*}{$\begin{array}{l}p \\
\text { value }\end{array}$} \\
\hline & & Agree (\%) & Disagree (\%) & Agree (\%) & Disagree (\%) & \\
\hline M1 & 4.27 & 69.4 & 30.6 & 62.3 & 37.7 & 0.11 \\
\hline M2 & 1.19 & 73.9 & 26.1 & 78.1 & 21.9 & 0.55 \\
\hline M3 & 0.71 & 60.9 & 39.1 & 62.3 & 37.7 & 0.70 \\
\hline M4 & 3.05 & 42.8 & 57.2 & 36.0 & 64.0 & 0.21 \\
\hline M5 & 0.78 & 71.4 & 28.6 & 31.6 & 68.4 & 0.67 \\
\hline M6 & 0.33 & 80.3 & 19.7 & 81.6 & 18.4 & 0.84 \\
\hline M7 & 3.23 & 79.6 & 20.4 & 86.8 & 13.2 & 0.19 \\
\hline M8 & 0.52 & 65.7 & 34.3 & 65.8 & 34.2 & 0.76 \\
\hline M9 & 0.45 & 69.7 & 30.3 & 70.2 & 29.8 & 0.79 \\
\hline M10 & 1.24 & 43.8 & 56.2 & 47.4 & 52.6 & 0.53 \\
\hline
\end{tabular}

M1-M10 are myth statements highlighted in Table 1 and the $p$ value is significant at $<0.05$. Each row represents one question. The percentage of agreement and disagreement for each gender and the $p$ value for the chi-square test of independence are shown 


\section{Abbreviations}

LBP: Low back pain; SD: Standard deviation; WMA: World Medical Association

\section{Supplementary Information}

The online version contains supplementary material available at https://doi. org/10.1186/s43161-021-00036-w.

Additional file 1. The full survey.

\section{Acknowledgements}

NA.

\section{Authors' contributions}

AS suggested the research idea, helped in the data collection, and analyzed and interpreted the data. He is the major contributor in the writing process. SS participated in the data collection and analysis. SQ and DP revised the data analysis, and they were contributors in the writing process. All authors read and approved the final version of the manuscript

\section{Funding}

The authors confirm that there is no financial support

\section{Availability of data and materials}

The data sets generated during and/or analyzed during the current study are available from the corresponding author on reasonable request.

\section{Declarations}

\section{Ethics approval and consent to participate}

The study was approved by the Institutional ethics committee, Lovely Professional University (LPU/IEC2019/03/13). Participants that participated in the study completed the survey after providing written informed consent.

\section{Consent for publication}

N/A

\section{Competing interests}

The authors declare that they have no competing interests.

\section{Author details}

'Department of Physiotherapy, Lovely Professional University, Phagwara, Punjab, India. ${ }^{2}$ Consultant Physiotherapist, New Hope Physiocare Physiotherapy Clinic, New Delhi, India. ${ }^{3}$ Physical Therapist, MT3 Teaching \& Consulting, Coon Rapids, Minnesota, USA.

\section{Received: 12 February 2021 Accepted: 11 June 2021}

\section{Published online: 08 September 2021}

\section{References}

1. Buchbinder R, van Tulder M, Öberg B, Costa LM, Woolf A, Schoene $M$, et al. Low back pain: a call for action. Lancet. 2018;391:2384-8. https://doi.org/1 0.1016/S0140-6736(18)30488-4.

2. Munigangaiah S, Basavaraju N, Jadaan DY, Devitt AT, McCabe JP. Do "Myths" of low back pain exist among Irish population? A cross-sectional study. Eur J Orthop Surg Traumatol. 2016;26(1):41-6. https://doi.org/10.1007/s00590-01 5-1698-y.

3. Wu A, March L, Zheng X, Huang J, Wang X, Zhao J, et al. Global low back pain prevalence and years lived with disability from 1990 to 2017: estimates from the Global Burden of Disease Study 2017. Ann Transl Med. 2020;8(6): 299. https://doi.org/10.21037/atm.2020.02.175.

4. Yiengprugsawan V, Hoy D, Buchbinder R, Bain C, Seubsman S, Sleigh AC Low back pain and limitations of daily living in Asia: longitudinal findings in the Thai cohort study. BMC Musculoskelet Disord. 2017;18(1):19. https://doi. org/10.1186/s12891-016-1380-5.

5. Goubert L, Crombez G, Bourdeaudhuij I. Low back pain, disability and back pain myths in a community sample: prevalence and interrelationships. Eur J Pain. 2004;8(4):385-94. https://doi.org/10.1016/j.ejpain.2003.11.004.

6. Cieza A, Causey K, Kamenov K, Hanson SW, Chatterii S, Vos T, Global estimates of the need for rehabilitation based on the Global Burden of
Disease study 2019: a systematic analysis for the Global Burden of Disease Study 2019. Lancet. 2020;396(10267):2006-17. https://doi.org/10.1016/S01406736(20)32340-0.

7. Bindra S, Sinha A, Benjamin A. Epidemiology of low back pain in Indian population: a review. Int J Basic Appl Med Sci. 2015;5:166-79 http://www. cibtech.org/J-MEDICAL-SCIENCES/PUBLICATIONS/2015/Nol_5_No_1/29-JMS029-BINDRA-EPIDEMIOLOGY-REVIEW.pdf.

8. Ahdhi G, Subramanian R, Saya G, Yamuna T. Prevalence of low back pain and its relation to quality of life and disability among women in rural area of Puducherry, India. Indian J Pain. 2016;30(2):111. https://doi.org/10.4103/ 0970-5333.186467.

9. Ganesan S, Acharya AS, Chauhan R, Acharya S. Prevalence and risk factors for low back pain in 1,355 young adults: a cross-sectional study. Asian Spine J. 2017;11(4):610-7. https://doi.org/10.4184/asj.2017.11.4.610.

10. Nasser MJ. How to approach the problem of low back pain: an overview. J Fam Community Med. 2005;12:3.

11. Campbell J, Colvin LA. Management of low back pain. BMJ. 2013;347:bmj. f3148. https://doi.org/10.1136/bmj.f3148.

12. Vasseljen $\mathrm{O}$, Woodhouse A, Bjrngaard JH, Leivseth L. Natural course of acute neck and low back pain in the general population: the HUNT study. Pain. 2013:154(8):1237-44. https://doi.org/10.1016/j.pain.2013.03.032.

13. Handa R. Low back pain- myths and facts. J Clin Orthop Trauma. 2019;10(4): 828-30. https://doi.org/10.1016/j.jcot.2019.05.024.

14. Meucci RD, Fassa AG, Faria NMX. Prevalence of chronic low back pain: systematic review. Rev Saude Publica. 2015;49:1-10. https://doi.org/10.1590/ S0034-8910.2015049005874.

15. Caneiro JP, Bunzli S, O'Sullivan P. Beliefs about the body and pain: the critical role in musculoskeletal pain management. Braz J Phys Ther. 2021; 25(1):17-29. https://doi.org/10.1016/j.bjpt.2020.06.003.

16. Picavet HSJ. Pain catastrophizing and kinesiophobia: predictors of chronic low back pain. Am J Epidemiol. 2002;156(11):1028-34. https://doi.org/10.1 093/aje/kwf136.

17. Campbell P, Foster NE, Thomas E, Dunn KM. Prognostic indicators of low back pain in primary care: five-year prospective study. J Pain. 2013;14(8): 873-83. https://doi.org/10.1016/j.jpain.2013.03.013.

18. O'Sullivan PB, Caneiro J, O'Sullivan K, Lin I, Bunzli S, Wernli K, et al. Back to basics: 10 facts every person should know about back pain. Br J Sports Med. 2020;54(12):698-9. https://doi.org/10.1136/bjsports-2 019-101611.

19. McCabe E, Jadaan D, Munigangaiah S, Basavaraju N, McCabe JP. Do medical students believe the back pain myths? A cross-sectional study. BMC Med Educ. 2019;19(1):235. https://doi.org/10.1186/s12909-019-1676-X.

20. Ihlebæk C, Eriksen HR. Are the "myths" of low back pain alive in the general Norwegian population? Scand J Public Health. 2003;31(5):395-8. https://doi. org/10.1080/14034940210165163.

21. O'Sullivan PB, Beales DJ, Smith AJ, Straker LM. Low back pain in 17 year olds has substantial impact and represents an important public health disorder: a cross-sectional study. BMC Public Health. 2012;12(1):100. https://doi.org/1 $0.1186 / 1471-2458-12-100$

22. World Medical Association. World Medical Association Declaration of Helsinki. JAMA. 2013;310:2191. https://doi.org/10.1001/jama.2013.281053.

23. Sharma S, Traeger AC, Reed B, Hamilton M, O'Connor DA, Hoffmann TC, et al. Clinician and patient beliefs about diagnostic imaging for low back pain: a systematic qualitative evidence synthesis. BMJ Open. 2020;10(8): e037820. https://doi.org/10.1136/bmjopen-2020-037820.

24. Pagare VK, Dhanraj T, Thakkar D, Sareen A, Palekar TJ. Beliefs about low back pain: status quo in Indian general population. J Back Musculoskelet Rehabil. 2015;28(4):731-7. https://doi.org/10.3233/BMR-140575.

25. Paller CJ, Campbell CM, Edwards RR, Dobs AS. Sex-based differences in pain perception and treatment. Pain Med. 2009;10(2):289-99. https://doi.org/1 0.1111/j.1526-4637.2008.00558.x.

26. O'Sullivan P. Diagnosis and classification of chronic low back pain disorders: maladaptive movement and motor control impairments as underlying mechanism. Man Ther. 2005;10(4):242-55. https://doi.org/10.1016/j.math.2 005.07.001.

27. Suri P, Boyko EJ, Goldberg J, Forsberg CW, Jarvik JG. Longitudinal associations between incident lumbar spine MRI findings and chronic low back pain or radicular symptoms: retrospective analysis of data from the Longitudinal Assessment of Imaging and Disability of the Back (LAIDBACK). BMC Musculoskelet Disord. 2014;15(1):152. https://doi.org/10.1186/1471-24 74-15-152. 
28. Tonosu J, Oka H, Higashikawa A, Okazaki H, Tanaka S, Matsudaira K. The associations between magnetic resonance imaging findings and low back pain: a 10-year longitudinal analysis. PLoS One. 2017;12(11):e0188057. https://doi.org/10.1371/journal.pone.0188057.

29. Brinjikji W, Luetmer PH, Comstock B, Bresnahan BW, Chen LE, Deyo RA, et al. Systematic literature review of imaging features of spinal degeneration in asymptomatic populations. Am J Neuroradiol. 2015;36(4):811-6. https://doi. org/10.3174/ajnr.A4173.

30. Webster BS, Bauer AZ, Choi Y, Cifuentes M, Pransky GS. latrogenic consequences of early magnetic resonance imaging in acute, work-related, disabling low back pain. Spine (Phila Pa 1976). 2013;38:1939-46. https://doi. org/10.1097/BRS.0b013e3182a42eb6.

31. Olaya-Contreras P, Styf J, Arvidsson D, Frennered K, Hansson T. The effect of the stay active advice on physical activity and on the course of acute severe low back pain. BMC Sports Sci Med Rehabil. 2015;7(1):1-9. https://doi.org/1 0.1186/s13102-015-0013-X.

32. Dahm KT, Jamtvedt G, Hagen KB, Brurberg KG. Advice to rest in bed versus advice to stay active for acute low-back pain and sciatica. In: Dahm KT, editor. Cochrane database of systematic reviews. Chichester: Wiley; 2009 https://doi.org/10.1002/14651858.CD007612.

33. Darlow B, Dowell A, Baxter GD, Mathieson F, Perry M, Dean S. The enduring impact of what clinicians say to people with low back pain. Ann Fam Med. 2013;11(6):527-34. https://doi.org/10.1370/afm.1518.

34. Buchbinder R, Jolley D, Wyatt M. 2001 Volvo award winner in clinical studies: effects of a media campaign on back pain beliefs and its potential influence on management of low back pain in general practice. Spine (Phila Pa 1976). 2001;26:2535-42. https://doi.org/10.1097/00007632-200112010-00005.

35. Buchbinder R, Jolley $D$. Effects of a media campaign on back beliefs is sustained 3 years after its cessation. Spine (Phila Pa 1976). 2005;30:1323-30. https://doi.org/10.1097/01.brs.0000164121.77862.4b.

36. Suman A, Schaafsma FG, Bamarni J, van Tulder MW, Anema JR. A multimedia campaign to improve back beliefs in patients with non-specific low back pain: a process evaluation. BMC Musculoskelet Disord. 2017;18(1): 200. https://doi.org/10.1186/s12891-017-1551-z.

37. Beales D, Smith A, O'Sullivan P, Hunter M, Straker L. Back pain beliefs are related to the impact of low back pain in baby boomers in the Busselton Healthy Aging Study. Phys Ther. 2015;95(2):180-9. https://doi.org/10.2522/ ptj.20140064.

\section{Publisher's Note}

Springer Nature remains neutral with regard to jurisdictional claims in published maps and institutional affiliations.

\section{Submit your manuscript to a SpringerOpen ${ }^{\circ}$ journal and benefit from:}

- Convenient online submission

- Rigorous peer review

- Open access: articles freely available online

- High visibility within the field

- Retaining the copyright to your article

Submit your next manuscript at $\boldsymbol{\nabla}$ springeropen.com 